\title{
Calidad físico-química y microbiológica del agua del municipio de Bojacá, Cundinamarca
}

\author{
Sandra Mónica Estupiñán Torres ${ }^{1}$, Sara Lilia Avila de Navia ${ }^{1}$ \\ 1 Docentes. Programa de Bacteriología y Laboratorio Clínico, Facultad de Ciencias de la Salud, Universidad \\ Colegio Mayor de Cundinamarca, Bogotá, Colombia.
}

Correspondencia: sestupinan@unicolmayor.edu.co

Recibido: 11-08-10 / Aceptado: 22-11-10

\section{Resumen}

Este estudio determinó si el agua para consumo humano del área urbana en el municipio de Bojacá Cundinamarca, cumplía con los parámetros físicos, químicos y microbiológicos establecidos en la Resolución 2 I I 5 de 2007. Para ello, se realizaron dos muestreos de diferentes puntos de la red de distribución, fuentes naturales y tanques de almacenamiento domiciliario. Se emplearon métodos fotométricos, electrométricos y volumétricos en los respectivos análisis físicos y químicos, para los parámetros microbiológicos se empleó la técnica de filtración por membrana. Los resultados obtenidos evidenciaron que la mayoría de las muestras no cumplió con en el valor mínimo permisible de cloro residual libre, por lo tanto, según el indice de riesgo de la calidad del agua para consumo humano (IRCA), son clasificadas como no aptas para consumo humano. Sin embargo, los demás parámetros analizados incluso los microbiológicos cumplieron los parámetros estipulados en la Resolución 21 I 5 de 2007. La calidad del agua debe mantenerse en todo el sistema de distribución, por lo tanto, además de llevar a cabo los procesos de potabilización, el prestador del servicio debe llevar un estricto control de los factores que puedan influir en la calidad del agua.

Palabras clave: Calidad del agua, agua potable, coliformes, Escherichia coli, IRCA, Red de distribución.

\section{Abstract \\ Physicochemical and microbiological water quality of Bojacá Township, Cundinamarca}

This study determined whether the drinking water in urban areas in the municipality of Cundinamarca Bojacá, met the physical, chemical and microbiological criteria established in Resolution 2 I I 5 of 2007. To this end, there were two samples from different parts of the distribution system, natural sources and storage tanks at home. Photometric, electrometric and volume methods were used in the respective physical and chemical analysis; additionally for microbiological parameters was used the membrane filtration technique. The results showed that most samples did not meet the minimum permissible value of free residual chlorine, therefore, according to the Risk Index Water Quality Water for human consumption (IRCA), are classified as non-unfit for human consumption. However, other microbiological parameters were met including the parameters set out in Resolution 2115 of 2007 . Water quality must be maintained throughout the distribution system. Therefore, in addition to carrying out the treatment processes, the service provider must keep a strict control of the factors that may affect water quality.

Key words: Quality of the water, drinkable water, Coliformes, Escherichia coli, IRCA, distribution network. 


\section{Introducción}

La cabecera municipal de Bojacá se abastece de agua de una fuente superficial nacedero y de un pozo, el agua proveniente del nacedero es tratada en una planta donde se lleva a cabo el proceso de microfiltrado y cloración y posteriormente por bombeo, llega a la red combinándose con el agua del pozo tratada en la planta urbana. La cobertura del servicio de acueducto en el área urbana es del $96 \%$ y beneficia a un total de 5904 usuarios (1).

Según la contraloría de Cundinamarca, en el periodo comprendido entre el ańo 2007 y el primer trimestre del 2008, la mayor parte de los acueductos en los municipios de Cundinamarca distribuyen a sus usuarios agua no potable. De los 116 municipios del departamento, el 45\% (52 municipios) no suministran agua apta para el consumo humano, de acuerdo con los valores establecidos en la Resolución 2115 de 2007. De un total de 1.529.427 cundinamarqueses (población proyectada por el DANE durante el año 2008), a 386.711 se les está suministrando agua no potable, lo que representa un $25 \%$ de la población total (2).

\section{Materiales y métodos \\ Área de estudio}

El Municipio de Bojacá está situado al occidente de la sabana de Bogotá, su superficie abarca cerca de $109 \mathrm{Km} 2$ y la altura sobre el nivel del mar es de 2.598 metros, con una temperatura media de $140 \mathrm{oC}$. El municipio cuenta con 8788 habitantes (3). El área urbana presenta mayor concentración de población con un total de 6151 habitantes, mientras que en el área rural la población llega a 2637 habitantes. En la actualidad, el acueducto tiene una cobertura en la zona urbana del 96\% (1).

\section{Toma de muestras}

Se realizaron dos muestreos y en cada uno se tomaron seis muestras de agua, los puntos de muestreo se indican en la Tabla.1. Las muestras se tomaron de acuerdo a la metodología establecida por la Norma Técnica Colombiana (NTC) 813, incluida en las normas oficiales para la calidad del agua en Colombia (4).

\section{Procesamiento de las muestras}

Se llevó a cabo la determinación de Coliformes totales y Escherichia coli (E. coli), con las recomendaciones del Standard Methods for the Examination of Water and Wastewater $(5,6)$, se empleó la técnica de Filtración por Membrana. El análisis físico químico se realizó mediante técnicas fotométricas, volumétricas y electrométricas respectivamente con los métodos que se indican en la Tabla 2.

\section{Determinación del índice de riesgo de la calidad del agua para consumo humano - IRCA}

De acuerdo a los resultados obtenidos en ambos muestreos se realizó el cálculo del índice de riesgo de la calidad del agua para consumo humano (IRCA), según lo indicado en la Resolución 2115 de 2007 (7).

\section{Resultados \\ Coliformes totales y E. coli \\ No se presentó crecimiento de Coliformes totales ni E. coli, en las muestras analizadas. \\ Color \\ El valor máximo aceptable es 15 Unidades Platino Cobalto (UPC), la muestra de agua proveniente de pozo en el segundo muestreo presentó un valor de 16 UPC, las demás muestras analizadas se mantuvieron por debajo de este valor, Figura 1.}

Tabla 1. Puntos de muestreo.

\begin{tabular}{ll}
\hline PUNTO & IMPORTANCIA \\
\hline $\begin{array}{l}\text { Pozo } \\
\text { Nacedero }\end{array}$ & Fuente de abastecimiento \\
$\begin{array}{l}\text { Tanque de almacenamiento posterior al tratamiento } \\
\text { (Agua de Pozo) }\end{array}$ & \\
Tanque de almacenamiento posterior al tratamiento & Efectividad tratamiento \\
(Agua Nacedero) & Efectividad tratamiento \\
Tanque de reserva domiciliario & Condiciones de almacenamiento \\
Grifo de domicilio & Punto entrega al consumidor \\
\hline
\end{tabular}


Tabla 2. Técnicas para la determinación de parámetros físico químicos del agua

\begin{tabular}{|c|c|c|c|}
\hline PARÁMETRO & $\begin{array}{l}\text { EQUIPOY } \\
\text { UNIDADES }\end{array}$ & $\begin{array}{l}\text { MÉTODO DE } \\
\text { DETERMINACIÓN }\end{array}$ & $\begin{array}{l}\text { PROCEDIMIENTO } \\
\text { BASADO EN }\end{array}$ \\
\hline Color & $\begin{array}{l}\text { Fotómetro } \\
\text { Nanocolor } 400 \mathrm{D} \\
\text { UPC (unidades de } \\
\text { platino cobalto) }\end{array}$ & - Fotométrico & DIN en ISO 7887-C1 \\
\hline $\mathrm{pH}$ & $\begin{array}{l}\text { Potenciómetro } \\
\text { WTW } 330 \mathrm{i}\end{array}$ & Electrométrico & DIN 19266 \\
\hline Turbiedad & $\begin{array}{l}\text { Turbidimetro } \\
\text { HANNA HI } \\
93703 \\
\text { UNT (unidades } \\
\text { nefelometricas) }\end{array}$ & - Nefelométrico & ISO 7027 \\
\hline Hierro & $\begin{array}{l}\text { Fotómetro } \\
\text { Nanocolor } 400 \mathrm{D}\end{array}$ & Fotométrico & $\begin{array}{l}\text { DIN } 38 \text { 406-E1-1. } \\
\text { Norma APHA 3500-Fe }\end{array}$ \\
\hline Alcalinidad Total & $\begin{array}{l}\text { Test Aquamerck } \\
\mathrm{mg} / \mathrm{L}\end{array}$ & Volumétrico & $\begin{array}{l}\text { Standard Methods for the } \\
\text { Examination of Water and } \\
\text { Wastewater } 2320\end{array}$ \\
\hline \multirow[t]{2}{*}{ Aluminio } & $\begin{array}{l}\text { Fotómetro } \\
\text { Nanocolor } 400 \mathrm{D}\end{array}$ & \multirow[t]{2}{*}{ - Fotométrico } & DIN E9-1989 \\
\hline & $\mathrm{mg} / \mathrm{L}$ & & Norma APHA 3500- Al-D \\
\hline Dureza Total & $\begin{array}{l}\text { Test Aquamerck } \\
\mathrm{mg} / \mathrm{L}\end{array}$ & - Volumétrico & $\begin{array}{l}\text { Standard Methods for the } \\
\text { Examination of Water and } \\
\text { Wastewater } 2340 \mathrm{C}\end{array}$ \\
\hline $\begin{array}{l}\text { Cloro residual } \\
\text { Libre }\end{array}$ & $\begin{array}{l}\text { Fotómetro } \\
\text { Nanocolor } 400 \mathrm{D} \\
\mathrm{mg} / \mathrm{L}\end{array}$ & Fotométrico & $\begin{array}{l}\text { DIN en ISO 7393-1-64-2 } \\
\text { Norma APHA 3500-Cl2 }\end{array}$ \\
\hline
\end{tabular}

\section{pH}

El valor establecido para este parámetro en la normatividad vigente está entre $6.5-9.0$, en este estudio todas las muestras analizadas cumplen con este valor, Figura 2.

\section{Color}

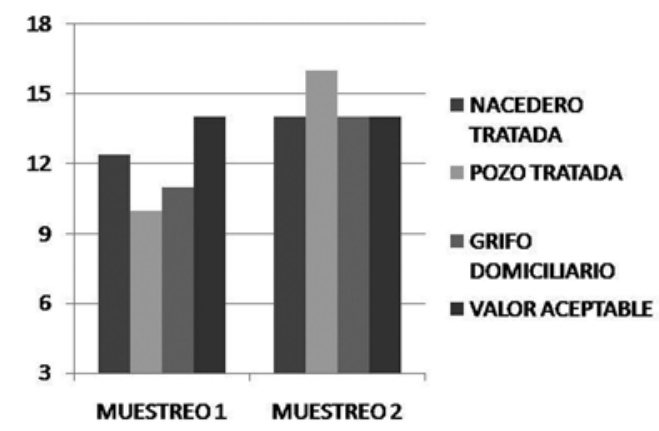

Figura 1. Resultados de color comparados con el valor máximo aceptable establecido en la Resolución 2115 de 2007.

\section{Turbidez}

Como se observa en la Figura 3 en todos los puntos muestreados el valor de este parámetro no superó el máximo aceptable de 2 Unidades Nefelométricas de Turbiedad (UNT).

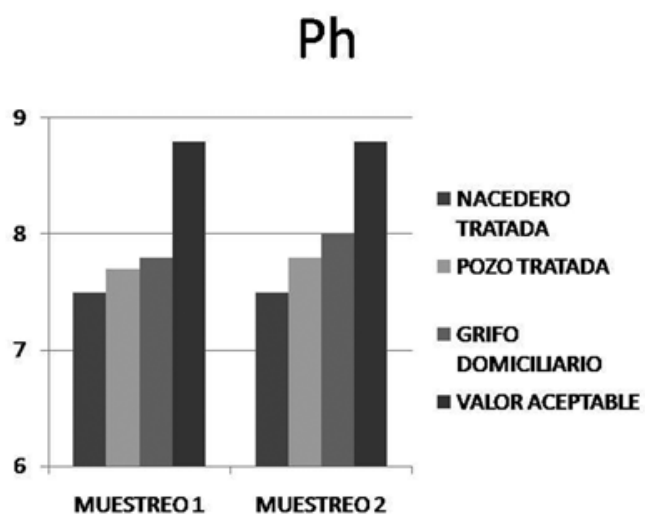

Figura 2. Resultados de $\mathrm{pH}$, comparados con el valor máximo establecido en la Resolución 2115 de 2007. 


\section{Turbidez}

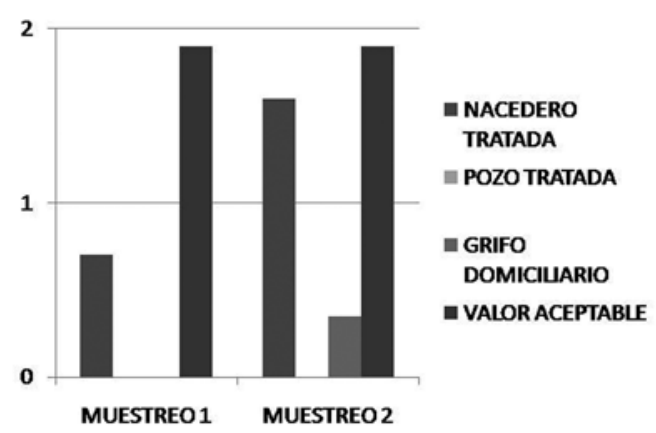

Figura 3. Resultados de Turbidez, comparados con el valor máximo establecido en la Resolución 2115 de 2007.

\section{Hierro}

Todas las muestras de agua analizadas se mantuvieron por debajo de $0.3 \mathrm{mg} / \mathrm{L}$, los resultados se pueden observar en la figura 4.

\section{Alcalinidad y dureza}

La alcalinidad y dureza en las muestras analizadas estuvieron entre valores de 90 a $140 \mathrm{mg} / \mathrm{L}$, manteniéndose por debajo del valor máximo permitido de 200 y $300 \mathrm{mg} / \mathrm{L}$ respectivamente, como se observa en las figuras 5 y 6 .

\section{Aluminio y cloro residual libre}

En los análisis de Aluminio $\left(\mathrm{Al}^{+3}\right)$, las muestras presentaron valores entre 0.15 y $0.16 \mathrm{mg} / \mathrm{L}$ encontrándose dentro del valor establecido en la

\section{Alcalinidad}

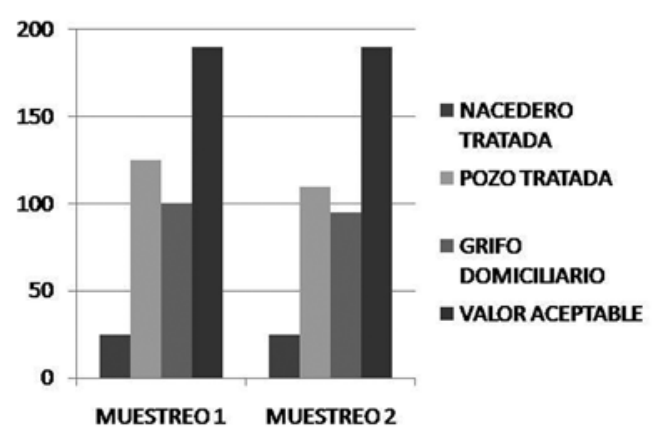

Figura 5. Resultados de Alcalinidad, comparados con el valor máximo aceptable establecido en la Resolución 2115 de 2007.

\section{Hierro}

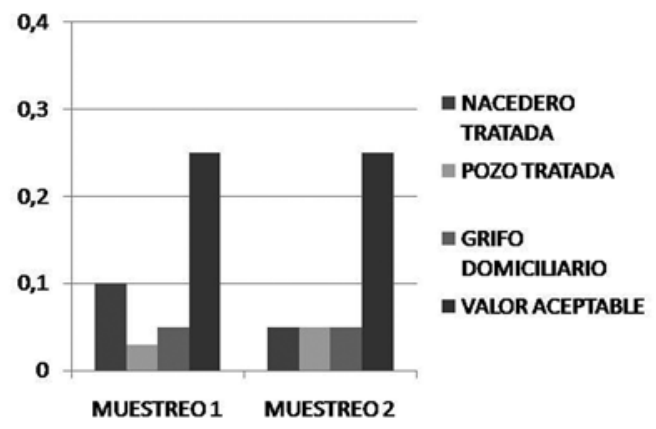

Figura 4. Resultados de hierro comparados con el valor máximo aceptable establecido en la Resolución 2115 de 2007

norma oficial (Figura. 7). En cuanto al cloro residual libre como se observa en la figura 7 en el primer muestreo se encontraron valores de 0.47 y $1.10 \mathrm{mg} / \mathrm{L}$ en las muestras de agua de pozo y nacedero tratadas, son valores aceptables, mientras que en la muestra de agua de grifo se encontró un valor de $0.22 \mathrm{mg} / \mathrm{L}$, el cual está por debajo del valor establecido ( 0.3 a 2.0 $\mathrm{mg} / \mathrm{L})$. En el segundo muestreo, solo la muestra de agua tratada proveniente del pozo estuvo dentro del rango aceptable con un valor de $0.7 \mathrm{mg} / \mathrm{L}$, mientras que las demás se encontraron por debajo de 0.2 mg/L, Figura 8.

\section{Determinación del IRCA}

En la tabla 3 se encuentran los valores de IRCA por muestra e IRCA mensual, según lo indicado en la Resolución 2115 de 2007.

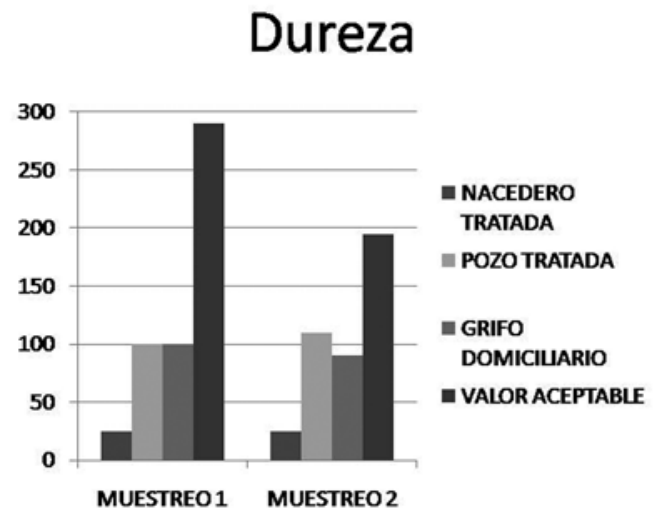

Figura 6. Resultados de dureza, comparados con el valor máximo aceptable establecido en la Resolución 2115 de 2007. 


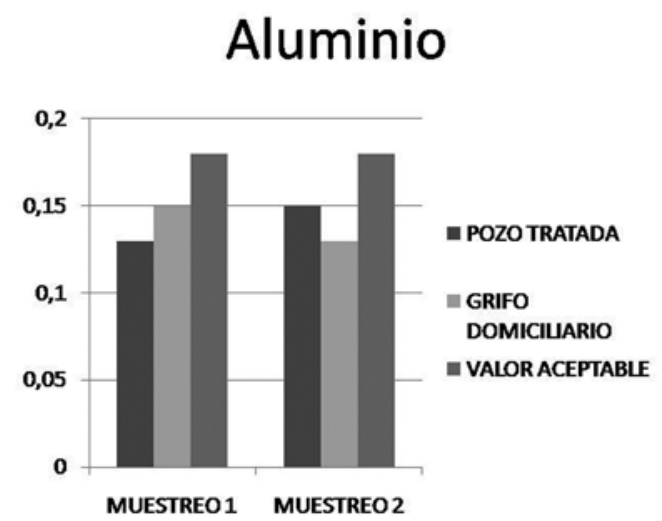

Figura 7. Resultados de Aluminio, comparados con el valor máximo aceptable establecido en la Resolución 2115 de 2007.

\section{Cloro Residual Libre}

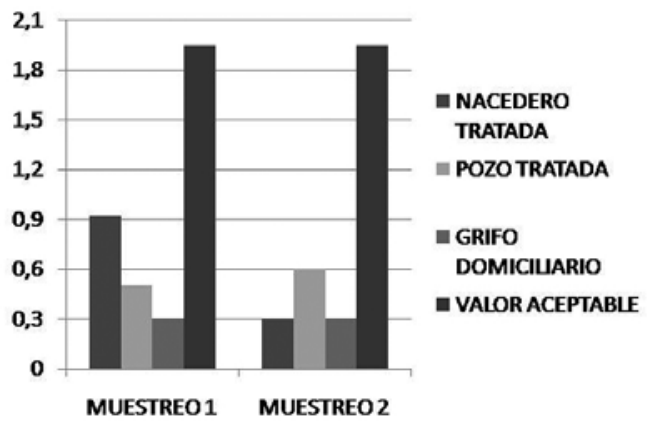

Figura 8. Resultados de Cloro residual libre, comparados con el valor máximo aceptable establecido en la Resolución 2115 de 2007.

Tabla 3. IRCA por muestra e IRCA mensual.

IRCA POR MUESTRA

NACEDERO TRATADA

\section{PRIMER MUESTREO}

$\operatorname{IRCA}(\%)=0 \times 100 / 81=0 \%$

\section{SEGUNDO MUESTREO}

$\operatorname{IRCA}(\%)=15 \times 100 / 81=17.8 \%$

\begin{tabular}{lll}
\hline POZO TRATADA & IRCA $(\%)=0$ X $100 / 84=0 \%$ & IRCA $(\%)=6$ X $100 / 84=7.1 \%$ \\
\hline GRIFO & IRCA $(\%)=15$ X $100 / 84=17.8 \%$ & IRCA $(\%)=15 \times 100 / 84=17.8 \%$ \\
\hline $\begin{array}{l}\text { IRCA MENSUAL } \\
\text { (PRIMER MUESTREO) }\end{array}$ & IRCA $(\%)=0 \%+0 \%+17.8 \% / 3=5.9 \%$ \\
\hline $\begin{array}{l}\text { IRCA MENSUAL } \\
\text { (SEGUNDO MUESTREO) }\end{array}$ & IRCA $(\%)=17.8 \%+7.1+17.8 \% / 3=14.2 \%$ \\
\hline
\end{tabular}

\section{Discusión}

\section{Agua no potable}

La alcalinidad de las muestras de agua de pozo, presentaron valores elevados, esto se debe probablemente a que la composición del suelo es de areniscas de naturaleza carbonatada, según lo reportado en el plan de ordenamiento territorial del Municipio de Bojacá (1), por el contrario las muestras provenientes de la fuente de agua superficial (nacedero) mostraron valores inferiores con respecto a los de pozo, ya que esta fuente presenta un lecho rocoso compuesto de granito y otras rocas ígneas pobres en carbonatos (1).

Para las muestras de agua de nacedero se reportan valores de $\mathrm{pH}$ de 7.5 y 7,6. Estos valores pueden afectar el proceso de desinfección, ya que como se indica en el Reglamento técnico del sector de Agua potable y Saneamiento básico RAS, el agua debe desinfectarse a un $\mathrm{pH}$ inferior a 7.5 pues valores superiores retardan las reacciones entre el cloro y el amoniaco, por esta razón es aconsejable mantener un $\mathrm{pH}$ entre 6 y 7 para lograr la eficiencia en el proceso de desinfección (8).

\section{Tanques de almacenamiento}

Aunque el Decreto 1575 de 2007 (9) indica que los tanques o reservorios de almacenamiento intradomiciliario no deben incluirse como puntos de muestreo para el control y la vigilancia de la calidad de agua para consumo humano, en este estudio se analizaron con el propósito de establecer si las condiciones de almacenamiento permitían mantener las características fisicoquímicas y microbiológicas del agua. Es importante tener en cuenta que no obstante el tratamiento sea efectivo, la calidad del agua puede disminuir cuando los usuarios no realizan el lavado de los tanques de almacenamiento domiciliarios que, 
según lo indica el Decreto 1575 en el artículo N. 10, debe realizarse como mínimo cada seis meses, de lo contrario se presenta acumulación de materia orgánica e inorgánica, que aumenta la turbidez e incrementa del consumo de cloro residual, como se pudo determinar en este estudio, donde este parámetro se encontró considerablemente disminuido (10).

Por otra parte, el hierro en el segundo muestreo, se encontró ligeramente aumentado con respecto al valor en las muestras de agua de las plantas de tratamiento. Estos resultados indican que hay cierta disminución de la calidad entre el agua que llega por la red y la que utiliza el usuario después del almacenamiento, resultados similares fueron presentados en un estudio realizado en la ciudad de Mérida, Yucatán, donde se observó que una vez que el agua llega a las casas, los sistemas de almacenamiento no mantienen la calidad con la que es distribuida (11). En los demás parámetros analizados los valores se mantuvieron estables, incluyendo los parámetros microbiológicos.

\section{Agua potable}

En las muestras de agua potable analizadas los parámetros de $\mathrm{pH}$, turbidez, hierro, alcalinidad, dureza y aluminio se encontraron dentro de los valores aceptables según lo establece la Resolución 2115 de 2007, por tanto se evidencia que la mayoría de los procesos de tratamiento, se realizaron de forma adecuada.

La muestra de agua tomada de la salida de la planta de tratamiento del pozo en el segundo muestreo, presentó una ligera elevación del parámetro color, con respecto al valor establecido en la Resolución, se puede suponer que alguno de los procesos empleados para la remoción de color (aireación, coagulación, sedimentación), no fue totalmente eficiente en este caso, ya que la muestra de agua de pozo presentó el valor más elevado dentro de las muestras de agua cruda analizadas. El color natural del agua puede alterarse por causas como la descomposición de la materia, materia orgánica del suelo, la presencia de hierro, manganeso y otros compuestos metálicos, además de otros factores como el $\mathrm{pH}$ y la temperatura (12); por tanto es indispensable revisar que los procesos empleados para remover color sean efectivos en el agua sometida a tratamiento.

Como se pudo observar en las muestras de agua tomadas de nacedero tratada primer muestreo y de grifo en los dos muestreos, los valores de cloro residual libre se encontraron por debajo del valor mínimo permisible (Figura 8), esta circunstancia evidencia que existen factores que están afectando los niveles de cloro residual libre como pueden ser la dosificación del cloro, un valor de $\mathrm{pH}$ superior a 7.5, la presencia de puntos muertos en las redes, la existencia de tuberías muy antiguas o averiadas, presencia de limo o biopelícula al interior de la tubería, que traen como consecuencia que el valor de cloro residual tienda a cero y exista la posibilidad de proliferación de microorganismos que puedan poner en riesgo la salud de los usuarios. Sin embargo, en este estudio no se pudo encontrar relación entre el bajo valor de cloro residual libre en las muestras de agua de grifo y la presencia de coliformes totales y E. coli.

Debido a que el prestador está incumpliendo con el parámetro de Cloro residual, al realizar el cálculo para el índice de riesgo de la calidad del agua para consumo humano (IRCA) las muestras de agua de grifo domiciliario en ambos muestreos presentaron un nivel de riesgo medio, lo cual las clasifica como no aptas para el consumo humano; por consiguiente es indispensable que el prestador lleve a cabo acciones correctivas, ya que, el incumplimiento de un único parámetro puede conllevar al rechazo del agua destinada al consumo humano. Según los resultados obtenidos, las muestras de agua analizadas son aptas microbiológicamente para consumo humano según lo establece la Resolución 2115, ya que no se presentaron recuentos de coliformes totales ni E. coli. IRCA

El índice de riesgo de la calidad del agua para consumo humano (IRCA), calculado para cada una de las muestras de agua del primer muestreo, clasificó las muestras de agua de nacedero tratada y pozo tratada (tanque de planta urbana) como agua sin riesgo, es decir, agua apta para consumo humano, mientras que la muestra de grifo obtuvo un puntaje que la clasifica dentro de un nivel de riesgo medio, debido a que el cloro residual libre se encontró por debajo del valor mínimo permitido, así mismo en el segundo muestreo, las muestras de agua de nacedero (tratada) y grifo, se encontraron dentro de un nivel de riesgo medio, por incumplimiento de 
este mismo parámetro, mientras que la muestra de pozo (tratada) se clasificó dentro de un nivel bajo, por incumplimiento en el parámetro de color; no obstante los demás parámetros en las muestras de agua analizadas se encontraron dentro de los valores establecidos en la Resolución 2115 de 2007.

\section{Agradecimientos}

Agradecemos especialmente a las estudiantes del Programa de Bacteriología de la Universidad Colegio Mayor de Cundinamarca Jeimy Tatiana Melo Vizcaíno, Yesica María Olaya Beltrán y Diana Marcela Ospina Chirivi. Al señor Uriel Tinoco, Secretario de Servicios Públicos de la Alcaldía Municipal de Bojacá y al señor Miguel Roa por su colaboración en la Planta de Tratamiento.

\section{Referencias}

1. Consejo Municipal de Bojacá Cundinamarca. Acuerdo No 012/04. Por el cual se adopta el Plan de desarrollo municipal. Bojacá, [en línea], [Revisado el 5 de Febrero de 2010]. Disponible en: www.planeacion. cundinamarca.gov.co/BancoMedios/Documentos $\% 20 \mathrm{PDF} /$ plan $\% 20$ de\%20desarrollo\%20definitivo7711.pdf

2. Contraloría de Cundinamarca. Informe sobre la calidad del agua potable en el departamento de Cundinamarca. Bogotá [en línea], [Revisado el 15 de Febrero de 2010]. Disponible en: www.contraloriadecundinamarca.gov.co/prensa/pdf-ambiental/12_parte.pdf

3. Información Municipal para la toma de decisiones. Bojacá, Cundinamarca. [Sitio en internet]. [Revisado el 20 de Junio de 2010]. Disponible en: http://bojaca-cundinamarca.gov.co/caafiles/663766303238663935303332383333337/bojaca.pdf

4. ICONTEC. Norma Técnica Colombiana 813, Normas oficiales para la calidad del agua en Colombia. Bogotá, ICONTEC [en línea] [Revisado el 15 de Marzo de 2010]. Disponible en: http://poseidon.unalmed.edu.
co/PGA/materias/funda_cont/docs/normas/agua potable/colombia

5. Standard Methods for the Examination of Water and Wastewater. Method 9222 B. Standard total coliform membrane filter procedure. 2003. [en línea]. [Revisado el 20 de Junio de 2010]. Disponible en: http://www.epa.gov/OGWDW/disinfection/lt2/pdfs/guide_lt2 mlmanual_appendix-k.pdf.

6. Standard Methods for the Examination of Water and Wastewater. Method 9222 Membrane Filter technique for members of the coliform group. [en línea], [Revisado el 20 de Junio de 2010]. Disponible en: http://etd.lib.fsu.edu/theses/available/etd-1103200431319/unrestricted/03_kap_supplement2.pdf.

7. Ministerio de la Protección Social, Ministerio de Ambiente, Vivienda y Desarrollo Territorial. Resolución 2115, Junio 2007, por medio de la cual se señalan características, instrumentos básicos y frecuencias del sistema de control y vigilancia para la calidad del agua para consumo humano. Bogotá: el Ministerio; [en línea] 2007 [fecha de acceso 5 de febrero de 2010]. Disponible en: http://www.minproteccionsocial.gov. $\underline{\text { co/VBeContent/NewsDetail.asp?ID }=16364 \& \text { IDCompany }=3}$

8. Ministerio de Desarrollo Económico. Dirección de Agua Potable y Saneamiento Básico. Reglamento técnico del sector de agua potable y saneamiento básico RAS - 2000, Sección II, Título C, Sistemas de potabilización. Bogotá D.C., RAS; 2.000. [en línea] [Revisado el 10 de Agosto de 2010]. Disponible en: http://www.cra.gov.co/portal/ www/section-30.jsp

9. Ministerio de la Protección Social. Decreto 1575 de 2007, Mayo 2007, por el cual se establece el Sistema para la Protección y Control de la Calidad del Agua para Consumo Humano. Bogotá: el Ministerio. 2007 [en línea], [Revisado el 10 de febrero de 2010]. Disponible en: http://www.minproteccionsocial.gov.co/VBeContent/NewsDetail. asp?ID $=16110 \&$ IDCompany $=3$

10. Marcó L, Azario R, Metzler C, et al. La turbidez como indicador básico de calidad de aguas potabilizadas a partir de fuentes superficiales. Higiene y Sanidad Ambiental. [En línea], [Revisado el 20 de Febrero de 2010]; 4: 72-82. Disponible en: http://publicacionesprograma.files. wordpress.com/2007/07/hig-sanid-ambient-4-72-82 .

11. Flores J, Suárez G, Franco M, et al. 1995. Calidad bacteriológica del agua potable en la ciudad de Mérida, Yucatán. Rev. Biomed. 6:127-134.

12. Centro Panamericano de Ingeniería Sanitaria y Ciencias del Ambiente (CEPIS/OPS). Tratamiento de agua para consumo humano. Manual I: Teoría. Capítulos 1 y 2 [en línea], [Revisado el 20 de Febrero de 2010]; Disponible en: http://www.cepis.org.pe/bvsatr/fulltext/tratamiento/ manualII/filtrarapmanual2.html. 